\title{
Els projectes Europeus Engaging Science, Xplore Health, RRI Tools i Scientix: Finestres a la formació i la participació en comunitats docents per al treball amb Controvèrsies i Recerca i Innovació Responsables
}

\author{
Sílvia Alcaraz-Domínguez (silvia.alcaraz@ub.edu) Universitat de Barcelona (Facultat d'Educació - \\ departament de Didàctica i Organització Educativa). \\ Mario Barajas (mbarajas@ub.edu) Universitat de Barcelona (Facultat d'Educació - departament de \\ Didàctica i Organització Educativa) i Coordinador nacional del projecte Europeu Engaging Science. \\ Rosina Malagrida (rmalagrida@irsicaixa.es) Unitat de Difusió de la Recerca Biomèdica. IrsiCaixa i Sots- \\ Coordinadora d'RRI Tools, Coordinadora d'XploreHealth. \\ Francisco Pérez (perez@ub.edu) Ambaixador Adjunt Scientix i INS Pompeu Fabra (Martorell).
}

L'ensenyament de les ciències als centres educatius ha de promoure la formació de ciutadans capaços de prendre decisions en contexts participats per la ciència, però també amb habilitats de discussió a partir d'evidències, presa de decisions $i$ valoració de riscs. Amb l'objectiu d'empoderar els ciutadans perquè la recerca s'alineï amb els valors socials, la Comissió Europea impulsa diversos projectes europeus destinats a oferir al professorat eines per a treballar les controvèrsies sòcio-científiques i la Recerca i Innovació Responsables, en diverses temàtiques (recerca biomèdica, nano-tecnologies, sostenibilitat, energia...). Es presenten diversos projectes europeus en aquesta línia juntament amb els recursos didàctics i les possibilitats de participació i formació.

Paraules clau: Controvèrsies, RRI, Projectes Europeus, Formació, Recursos Didàctics.

Science Education in Schools has to promote the education of citizens able to take decisions on science-participated contexts. Discussing on evidences, taking decisions and risks evaluation are necessary skills to this end. With the goal to empower citizens and aligning research with the values of society, the European Commission foster several educational projects on Socio-Scientific Issues and Responsible Research and Innovation on several topics (nano-technologies, biomedical research, sustainability, energy,...). We present in this article several European Projects together with its didactic resources and participation and training opportunities.

Keywords: Socio-Scientific Issues, RRI, European Projects, Teacher-Training, Didactic Resources.

\section{INTRODUCCIó}

\section{Què és la RRI i perquè ara?}

La Recerca i la Innovació (R\&I) ens aporten solucions a molts dels problemes socials de la nostra societat basada en el coneixement. Els nous productes i serveis que se'n deriven, van donant forma al món en el què vivim i tenen un significant impacte a les nostres vides. No obstant, els ciutadans rarament estan involucrats en processos democràtics per definir quina innovació volem. 
D'altra banda, un cop els resultats de l'R\&I estan al mercat, els ciutadans han de decidir si volen fer-ne ús, i molt sovint no tenen el coneixement i les competències necessàries per prendre decisions informades. Finalment, encara hi ha un ampli ventall de reptes socials per identificar i resoldre, mentre que, al mateix temps, la innovació ens aporta nous productes i serveis que de vegades no responen a reptes socials existents, i que requereixen d'intenses campanyes de màrqueting per provocar la necessitat.

En aquest context, es requereix reconsiderar la governança de la ciència, el seu rol dins la societat i com ha de ser el procés que determina que una R\&I sigui d'excel•lència. L'objectiu d'aquest necessari canvi estructural de l'R\&I se centra en millorar la qualitat de la recerca per assegurar-nos que els seus resultats estan més en línia amb les necessitats i les expectatives de la societat. Per assolir aquest objectiu, l'R\&I ha de dur-se a terme d'una manera més oberta i inclusiva i s'ha de desenvolupar amb la col•laboració de diferents actors socials (industria, investigadors, entitats de la societat civil, polítics, directius, educadors, estudiants i les seves comunitats). Aquest nou paradigma de l'R\&I s'anomena Recerca i Innovació Responsables (RRI, de les seves sigles en anglès) (Comissió Europea, 2012) i ha anat prenent força en diferents àmbits de la societat.

\section{Perquè RRI a l'escola?}

La Comissió Europea (CE) ha identificat 6 línies d'actuació que cal incloure al full de ruta dels diferents països membres per implementar els canvis necessaris en el sistema d'R\&I: igualtat de gènere, accés obert, ètica, participació ciutadana, governança i educació en ciències. Però per facilitar que aquestes agendes es puguin dur a terme adequadament, Europa necessita una ciutadania apoderada amb coneixement i amb competències per al raonament científic i l'anàlisi crític que estigui disposada a participar en processos i en decisions d'R\&I (Comissió Europea, 2014a i 2014b).

Els principis de la RRI estan tenint un impacte en l'ensenyament de les ciències, sobretot a l'educació secundària. Tant a nivell de Catalunya com a l'Estat Espanyol, trobem una presència de continguts clarament relacionats amb la RRI, com "Conèixer $i$ valorar les interaccions de la ciència i la tecnologia amb el medi ambient', segons la Ley Orgánica de Educación (Ministerio de Educación, 2006); o "Utilitzar el coneixement científic per argumentar de manera fonamentada $i$ creativa les actuacions com a ciutadans $i$ ciutadanes responsables" segons el currículum a Catalunya (Departament d'ensenyament, 2009). Concretament, en el document de desplegament de les competències bàsiques de l'àmbit científictecnològic per a l'educació secundària, destaca la finalitat humana i social de l'activitat científica (Departament d'Ensenyament, 2014). El nou currículum LOMCE subratlla aquesta orientació incloent les matèries de Cultura Científica i Ciències Aplicades a l'Activitat Professional.

Per aquestes raons, podem afirmar que les assignatures de ciències com la biologia, la geologia, la física o la química ja no es poden ensenyar com un conjunt de coneixement estàtic creat pels científics. Al contrari, la nova competència científica inclou la capacitat de participar activament en la presa de decisions científiques.

Un dels factors d'èxit del canvi cap a aquesta nova concepció de la competència científica és el professorat (Fullan i Hargreaves, 1992). En el context de la RRI, el professorat ha d'ajudar a l'alumnat a desenvolupar una actitud crítica davant les novetats i notícies científiques que es publiquen, a valorar els riscs d'una solució científica o tecnològica, o a argumentar científicament. És a dir, el professorat ha d'adquirir un domini d'uns continguts i mètodes que tradicionalment no han estat associats a l'ensenyament de les ciències experimentals. De la mateixa manera, i segons el model de Pedagogical Content Knowledge (Schulman, 1986), el professorat ha d'actualitzar el seu coneixement pedagògic o relatiu a la metodologia en funció dels canvis en el currículum.

\section{RECURSOS I PROPOSTES}

\section{Engaging Science: Recursos digitals i formació virtual per al professorat de ciències basats en els principis de la Investigació i la Innovació Responsables}

Per tal d'ajudar al professorat a fer front a aquests reptes, la Universitat de Barcelona participa al projecte "Equipping the next generation for an active engagement in Science" (ENGAGE). El projecte proposa introduir controvèrsies científiques que ajudin a la comprensió dels fenòmens des d'una perspectiva de RRI.

Un dels grans eixos del projecte és un repositori de recursos didàctics en format digital [1]. Aquests recursos permeten assolir els objectius del currículum partint de notícies científiques recents i 
controvertides. Es poden descarregar de manera gratuïta i modificar-los segons les necessitats del docent i seguint la Llicència Creative Commons3.0 [2].

Cada recurs inclou una presentació gràfica, fitxes per a l'alumnat i guia del professorat, tal com es mostra a la Figura 1. A partir de la controvèrsia plantejada, es proposen activitats d'indagació basades en el model de les 5 E's (Bybee et al, 2006).

Per exemple, una de les activitats parteix de la pregunta "Provaries una vacuna contra l'Ėbola?". Després d'expressar les seves primeres reaccions, l'alumnat aplica els seus coneixements sobre genètica per tal d'explicar com funciona aquesta vacuna. A continuació, recullen informació sobre els riscs $\mathrm{i}$ els beneficis associats a la prova d'aquesta vacuna, els valoren i prenen una decisió. Finalment, reflexionen sobre la decisió presa i les raons que els han portat a fer-ho. Aquesta activitat incorpora el vessant RRI no només perquè permet aplicar coneixements disciplinars a una situació real, sinó també perquè ajuda a entendre, des d'una metodologia d'indagació, com es formen les creences o l'opinió pública sobre un procés científic com és la comercialització d'una nova vacuna.

Per tal d'aprofundir en els fonaments pedagògics dels recursos educatius, el projecte ofereix tallers presencials $\mathrm{i}$ formació virtual per al professorat [3]. Un exemple de la formació virtual es pot trobar en el curs "Controversias científicas e indagación para la enseñanza de las ciencias" [4]. Aquesta formació es basa en un model pedagògic en tres nivells que permetrà al professorat integrar els principis de la RRI a l'aula. Concretament, la formació inicial es centra en el concepte de controvèrsia científica i l'estratègia didàctica del debat científic en grups reduïts. A la formació avançada, el professorat aprèn com utilitzar l'aprenentatge basat en problemes i com ajudar a l'alumnat a participar en converses científiques. Finalment, la formació de nivell expert es centra en l'aprenentatge basat en projectes i l'avaluació.
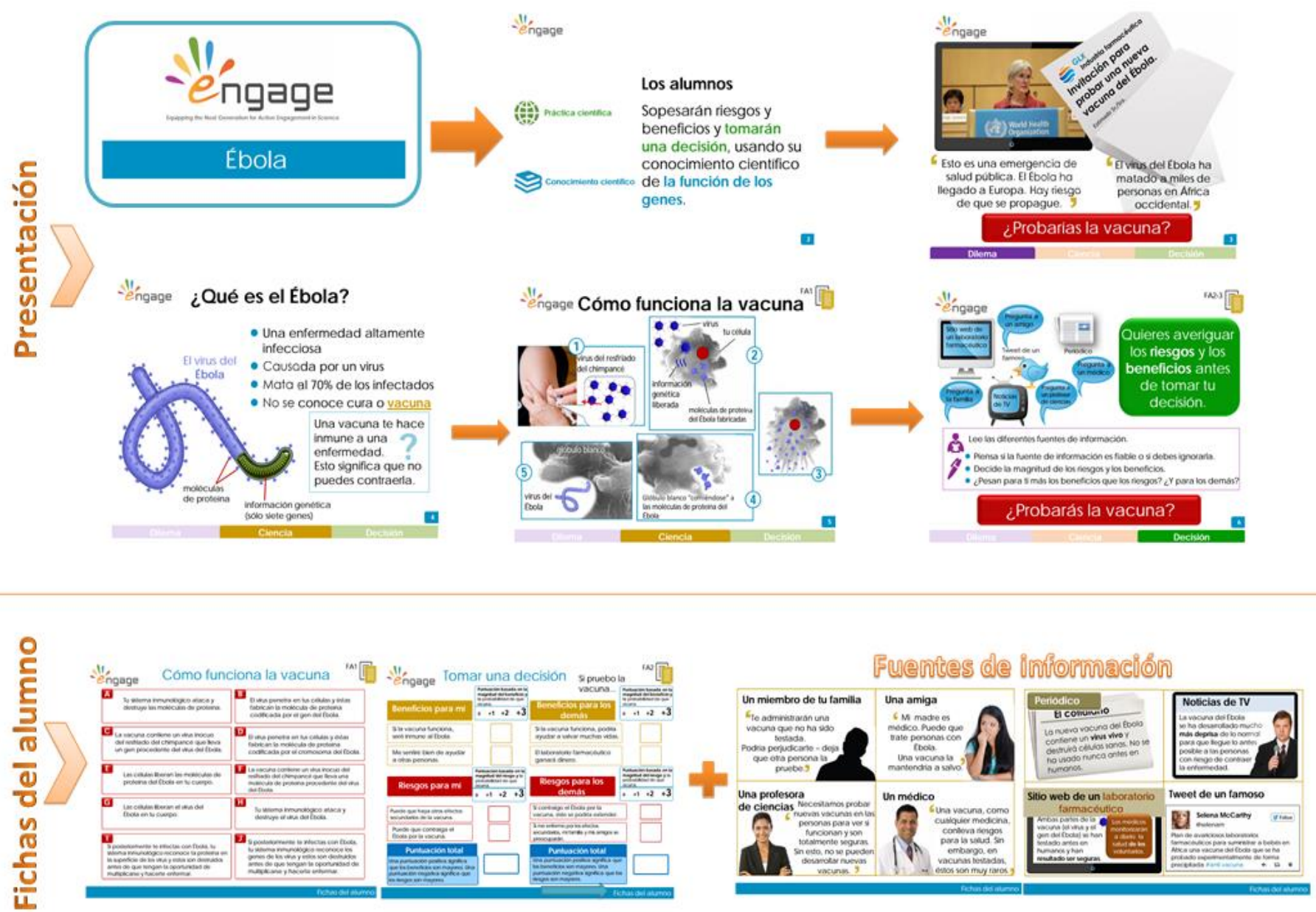

Figura1. Recurs didàctic disponible a http://www.engagingscience.eu/es/ per a la seva descàrrega gratuïta. 


\section{Scientix: recursos per l'aula sobre controvèrsies sociocientífiques i recerca i innovació responsables}

Scientix és una comunitat per a l'ensenyament de les ciències a Europa finançada per la Comissió Europea a través del 7è Programa Marc i gestionada per la xarxa europea European Schoolnet (EUN). És una iniciativa oberta a la participació de docents, investigadors, responsables d'elaboració de polítiques, actors locals, pares i mares, i qualsevol persona interessada en l'educació científica. El projecte neix per facilitar la constant divulgació i intercanvi de coneixements tècnics i exemples pràctics en l'ensenyament de les ciències a la Unió Europea, i recopila materials didàctics i informes d'investigacions de projectes europeus.

El banc de recursos de Scientix ofereix molts recursos de temes de recerca i innovació responsables i controvèrsies sòcio-científiques vinculades a temàtiques actuals (Figura 2), creats en el marc de projectes europeus en Ensenyament de les Ciències.

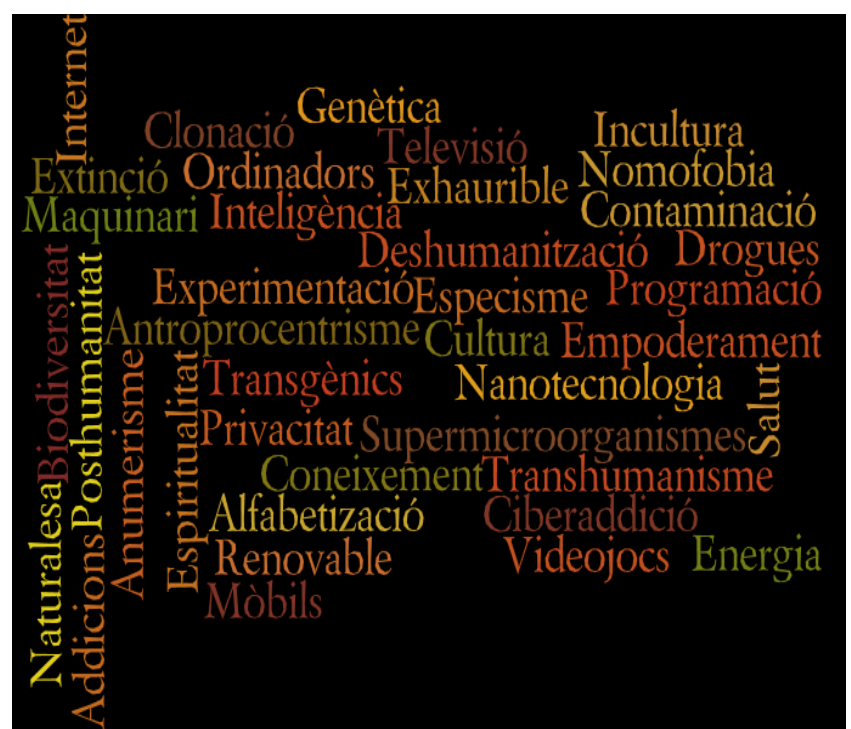

Figura 2. Temes d'activitats relacionades amb controvèrsies sociocientífiques trobades a la web de recursos Scientix.

\section{"Esteu llestos? Un joc de rol sobre la utilització de cèl-lules mare" . Projecte EuroStemCell[6]}

L'objectiu del joc és l'aprovació d'un assaig clínic que utilitzarà cèl•lules mare embrionàries humanes per tractar lesions de la medul•la espinal. Els alumnes juguen diferents papers del Comitè Ėtic d'Investigació Clínic (investigador en cèılules mares, representant dels pacients amb lesions de la medul•la espinal, expert en bioètica i neurocirurgià) o del públic (lesionat medul•lar, activista pro-vida, empresari biotecnològic, representat dels discapacitats, activista protecnologia i propietari d'una cafeteria). Als estudiants reben informació sobre cèl-lules mare $i$ lesió medul•lar així com targetes biogràfiques dels seus personatges, i se'ls plantegen diverses qüestions en el marc d'un joc de rol: Per què s'utilitzen embrions per la investigació sobre cèl/lules mare? ¿l què passa amb les cèl/lules mare vénen de teixits adults? Quins són els riscos comparats amb els beneficis? On hem de posar els límits? A qui pertanyen els resultats de la investigació i/o els resultats mèdics: als científics, les companyies, al Govern, o a la societats? Com afecta la competència entre científics a la recerca?

\section{Experimentació animal. Projecte KitPlayDecide [5]}

Es tracta d'una activitat estructurada sobre els límits en el desenvolupament de nous fàrmacs i el patiment dels animals d'experimentació.

En el kit es disposa d'uns arxius PDF que s'imprimeixen en cartolina de color (Figura 3) i juguen entre 4 i 8 persones durant uns 80 minuts. En una primera fase informativa els jugadors trien una targeta d'informació i trien dos de tema, podent afegir informacions en cartes blanques. En una segona fase es discuteix de forma lliure o amb torns, emprant targetes de desafiament per estimular la discussió. Durant aquesta fase, els jugadors fan servir les targetes per sostenir els seus arguments. Els alumnes posen sobre la taula les seves targetes per discutir i poden agrupar-les per intentar trobar una visió del grup. En una tercera fase es vota una resposta compartida de grup entre 4 postures polítiques o es proposa una cinquena. Finalment es poden pujar resultats al web del projecte.

Al portal del projecte es poden també trobar recursos relacionats amb diverses controvèrsies científiques, com l'Estalvi Energètic, les Cèl•lules mare, Animals d'experimentació, Autodiagnòstics de salut, Epidèmies sanitàries, el Negoci de l'alimentació, Construcció de pistes d'esquí, Nanotecnologia...

Altres recursos que s'inclouran a la web de recursos de Scientix seran els resultats del projecte Erasmus+ en curs sobre creativitat tecnològica i artística (www.arteducation.eu). En aquest projecte es reflexionarà des d'un punt de vista socio- 
tecnològic de nous avenços en nanotecnologies,

Arduino, realitat augmentada i art.

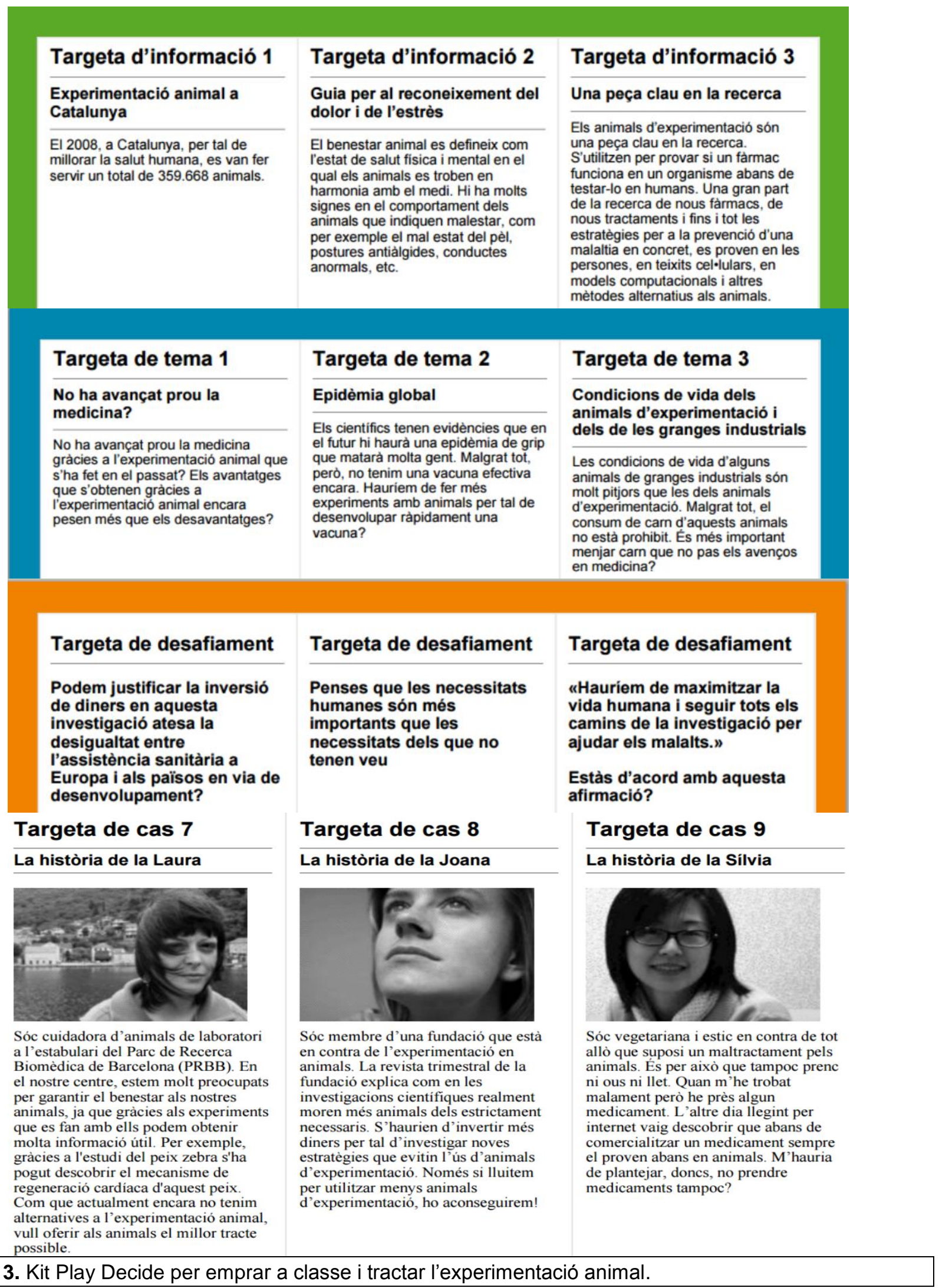

Figura 3. Kit Play Decide per emprar a classe i tractar l'experimentació animal. 


\section{Xplore Health, facilitant una millor relació entre la recerca biomèdica i l'educació}

Xplore Health és un programa educatiu innovador que té com a finalitat disminuir el distanciament entre recerca i educació amb l'objectiu d'apoderar estudiants perquè entrin al sistema d'RRI i es converteixin en ciutadans responsables de la nostra societat del coneixement. Xplore Health ofereix un portal [7] amb recursos multimèdia conjuntament amb eines que fomenten la participació i l'experimentació a l'aula amb la finalitat d'oferir informació sobre R\&l i no només sobre el què sinó també sobre el com, és a dir sobre com es duen a terme els projectes de recerca. Dins d'aquesta modalitat s'inclouen experiments virtuals, vídeos i jocs on-line. D'altra banda, el portal també promou la reflexió i el diàleg sobre aspectes ètics, legals i socials relacionats amb l'R\&I mitjançant vídeos que inclouen diferents opinions d'experts $\mathrm{i}$ jocs de cartes en diferents formats (Play Decide i Discussion Continuum). Aquests es troben disponibles en documents que només cal imprimir, retallar i facilitar als alumnes a les aules [8].
La combinació dels recursos informatius amb els que fomenten la reflexió faciliten una oportunitat única per a que l'alumnat pugui endinsar-se i participar en l'actualitat científica. Per facilitar-ho, el portal també ofereix Documents de treball per a l'alumnat que promouen la indagació i la interacció dels estudiants amb els diferents actors socials citats anteriorment. El conjunt de recursos ha tingut molt bona acollida a les aules, essent recollit al catàleg de bones pràctiques $\mathrm{RRI}$ elaborat per el projecte europeu RRI Tools (Kupper et al, 2015).

Xplore Health també ofereix un extens programa d'activitats presencials que combina cursos per a Professorat amb oportunitats per als estudiants de participar en tallers d'experiments contextualitzats en projectes de recerca actual, i on duen a terme pràctiques de laboratori amb instruments i reactius reals dels centres de recerca on s'estan impartint les línies de recerca. A tall d'exemple, un dels experiments es du a terme amb un candidat a vacuna contra el VIH que l'Institut de Recerca de la Sida està desenvolupant. Els protocols es troben disponibles al portal [9].

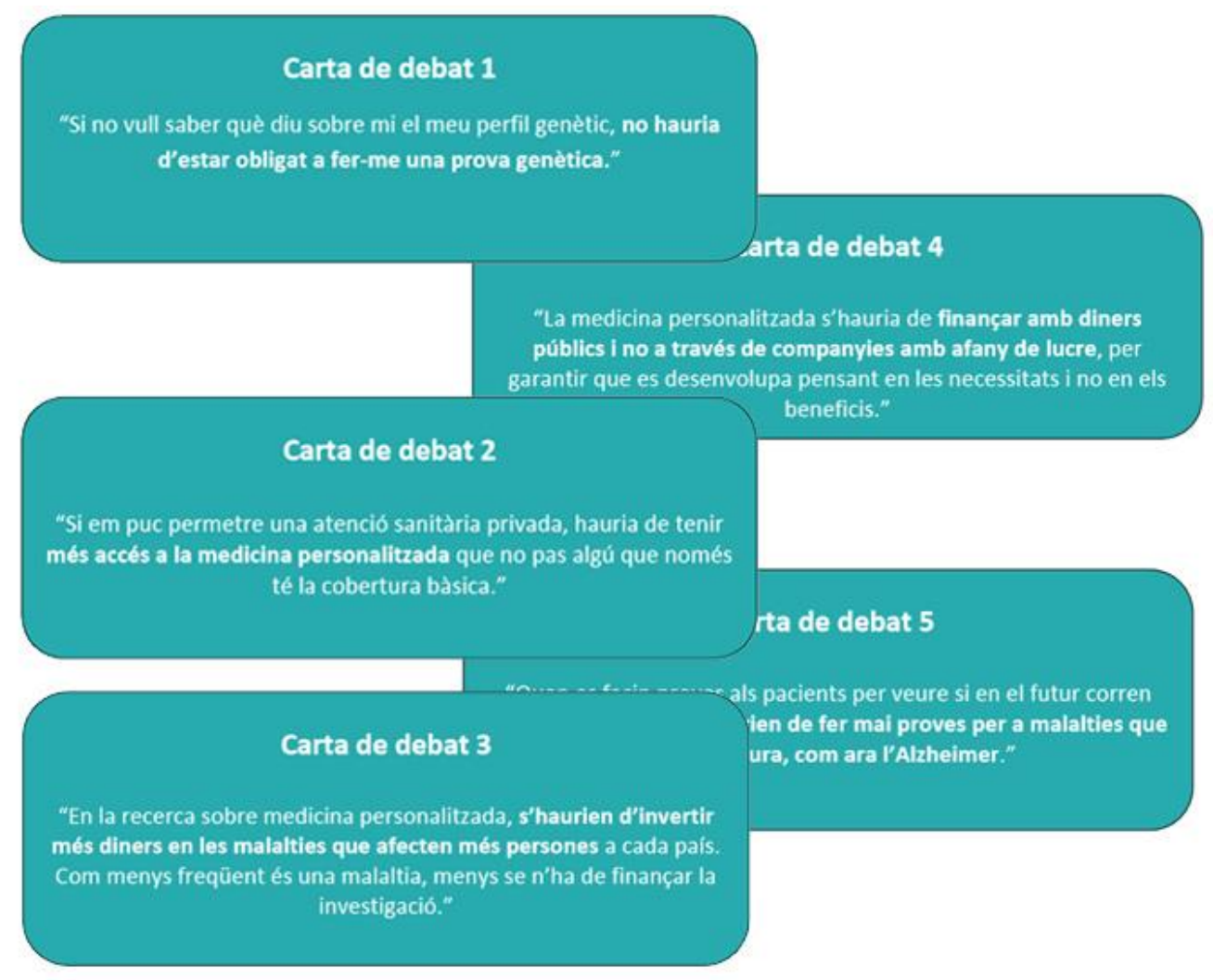

Figura 4. Imatge de les Cartes de Debat de l'activitat de l'activitat sobre Medicina personalitzada del portal Xplore Health. Les activitats inclouen eines per al treball amb debats a l'aula, com les cartes de debat proposant visions o opinions perquè els alumnes es posicionin al respecte. 
Aquestes activitats s'ofereixen des dels anomenats Clusters d'XploreHealth, que es troben localitzats a centres de recerca i museus de ciències d'arreu de l'Estat espanyol i ofereixen al professorat la possibilitat de participar en una Xarxa de Centres Pilot, des d'on se'ls facilita accés a seminaris de formació entorn a metodologies educatives innovadores i RRI.

També se'ls dóna accés a una plataforma online a través de la qual poden intercanviar bones pràctiques, participar en una avaluació anual així com participar en projectes educatius sobre RRI i recerca comunitària. Actualment el programa d'activitats es coordina des de tres Clusters: el museu Domus de Galícia, el Parque de las Ciencias de Granada i IrsiCaixa i el CosmoCaixa a Barcelona. Així mateix, l'Obra Social "la Caixa" també ofereix tallers des dels seus CaixaForums i des d'un laboratori itinerant. Properament està prevista l'apertura d'un nou Clúster a Madrid.

\section{CONCLUSIONS I PERSPECTIVES}

Els recursos proposats contribueixen a disminuir el distanciament entre ciència $i$ societat $i$ entre recerca i educació i, alhora, promouen la formació d'estudiants que interactuen amb diferents actors socials com a ciutadans responsables i participatius, amb l'objectiu de contribuir a posar el seu granet de sorra per millorar el sistema de ciència i innovació tot i fen-lo més democràtic.

A més dels diversos recursos didàctics proposats, els diferents projectes organitzen cursos de formació per al professorat i tenen per objectiu la formació de xarxes de professorat que treballa amb CSC i RRI.

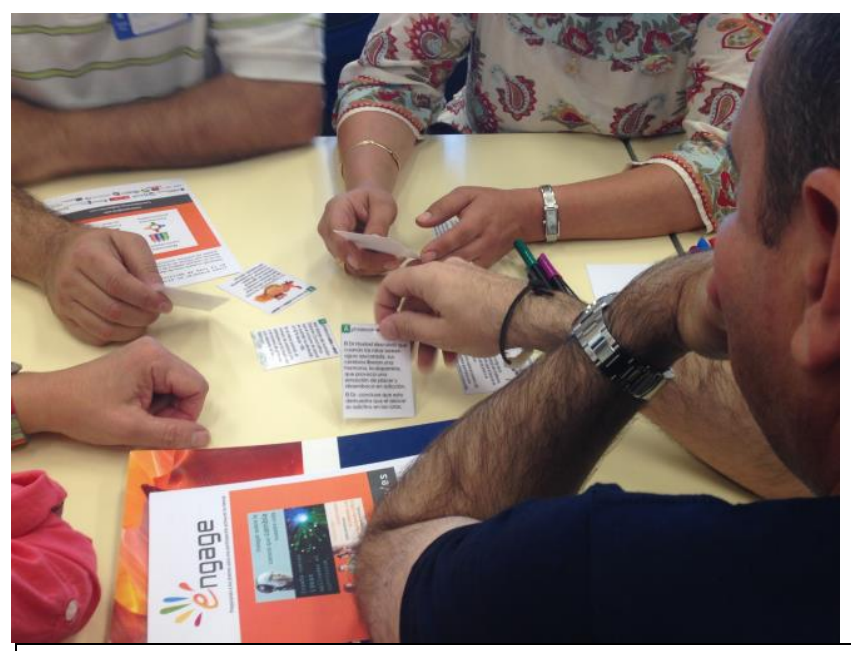

Figura 5. Professorat de ciències coneixent els recursos d'Engaging Science durant un seminari presencial
La participació en els projectes està oberta a qualsevol docent interessat/da, en els nivells d'educació primària, secundària, batxillerat, formació professional i estudis superiors. Existeixen diferents modalitats de participació en el projecte. Com a docent, és possible registrar-se als repositoris de recursos i descarregar-los. En tots els projectes presentats els recursos s'ofereixen en diverses llengües i existeix la possibilitat de demanar la traducció gratuïtament a través del portal Scientix.

El projecte Europeu RRI Tools mencionat breument en aquest article acull sota el seu paraigües altres projectes europeus que poden ser també d'interès per al lector, com els projectes InGenious, PRogreSS [10], GenPort, Socientize [11], Engage2020, Responsible Industry [12], Responsability o GREAT [13].

Des de perspectives complementàries sobre les CSC, el lector pot trobar d'interès també materials d' altres articles publicats en aquest mateix número de la revista ciències (Farró et al, 2015, DomènechCasal, Marchán i Vergara, 2015) com a part de les Jornades sobre Controvèrsies Sòcio-Científiques i Recerca i Innovació Responsables \#cscrri15 (Domènech-Casal i Lope, 2015).

\section{AGRAIIMENTS}

Aquest article recull el contingut de tres ponències presentades pels autors a les "Jornades de Controvèrsia Sòcio-Científica $i$ Recerca $i$ Innovació Responsables. Ciències per a qüestionar i canviar el món. Pensar, comprendre, decidir." (https://cienciaicontroversia.wordpress.com) que es van celebrar els dies 21-X, 4-XI i 25 XI de 2015 al CESIRE de Barcelona (Drassanes) del Departament d'Ensenyament de la Generalitat de Catalunya.

Iniciatives descrites formen part d'un projecte competitiu en el que participa la Universitat de Barcelona (Inv. Principal: Mario Barajas) finançat amb l'ajuda de la Comissió Europea anomenat "Equipping the next generation for an active engagement in Science (ENGAGE)".

Recursos proposats en aquest article pertanyen a la xarxa Scientix i han rebut el recolzament del programa europeu Erasmus+ 2015-1-RO01KA2019-015106 (www.arteducation.eu).

S'agraeix el suport de la l'Obra Social "la Caixa", Amgen i IrsiCaixa i la col•laboració de l'equip coordinador de l'Obra Social "la Caixa" i d'IrsiCaixa: Ignasi López Verdaguer, Guillermo Santamaría, 
Daniel García, Belén Perat, Josep Carreras, i col•laboradors externs com Laia Corbella, Marcel Costa, Miquel Nistal, Lluís Pagès, i Montse Colille.

\section{BIBLIOGRAFIA}

BYBEE, R. W., TAYLOR, J. A., GARDNER, A., VAN SCOTTER, P., POWELL, J. C., WESTBROOK, A., i LANDES, N. (2006). The BSCS 5E instructional model: Origins and effectiveness. Colorado Springs, CO: BSCS, 5, 88-98.

COMISSIÓ EUROPEA (2012). Responsible Research and Innovation. Europe's ability to respond to societal challenges. European Union. [https://ec.europa.eu/research/swafs/pdf/pub_pu blic_engagement/responsible-research-andinnovation-leaflet_en.pdf ]

COMISSIÓ EUROPEA (2014a). Responsible Research and Innovation. Europe's ability to respond to societal challenges. [https://ec.europa.eu/research/swafs/pdf/pub_rri/ KI0214595ENC.pdf]

COMISSIÓ EUROPEA (2014b). Science With and for Society. [http://ec.europa.eu/research/swafs/index.cfm?p $g=$ policy\&lib=education]

DEPARTAMENT D'ENSENYAMENT. (2009). Currículum. Educació Secundària. Barcelona: Generalitat de Catalunya.

DEPARTAMENT D'ENSENYAMENT (2014). Competències bàsiques de l'àmbit científicotecnològic. Educació Secundària. Barcelona: Generalitat de Catalunya.

DOMĖNECH-CASAL, J., LOPE, S. (2015). Les Jornades de Controvèrsia Sòcio-Científica $i$ Recerca i Innovació Responsables. Ciències per a qüestionar $i$ canviar el món. Pensar, comprendre, decidir. Revista Ciències (aquest mateix número).

DOMĖNECH-CASAL, J., MARCHÁN, I., VERGARA, E. (2015). Experiències d'aula amb el treball amb Controvèrsies Sòcio-Científiques. Educació per al Desenvolupament i la Salut, Pseudociències $i$ eines per a l'avaluació d'activitats. Revista Ciències (aquest mateix número).

FARRÓ, L., LOPE, S., MARBÀ, A., OLIVERAS, B. (2015). Les Controvèrsies Sòcio-Científiques com a contextos d'aprenentatge i comunicació a l'aula. Anàlisi crítica de la informació $i$ habilitats comunicatives. Revista Ciències (aquest mateix número).
MINISTERIO DE EDUCACIÓN. Ley Orgánica 2/2006, de 3 de mayo, de Educación. BOE, 4 de mayo de 2006, número 106, p. 17158-17207

FULLAN, M., HARGREAVES, A. (1992) (Eds.) Teacher development and educational change. London: The falmer press

KUPPER, F., KLAASSEN, P., RIJNEN, M.,VERMEULEN, S., WOERTMAN, R., BROERSE, J. (2015). A catalogue of good RRI practices. RRI Tools. Athena Institute, VU University Amsterdam [http://www.rritools.eu/documents/10182/18424/RRITools_D1. 4-CatalogueOfGoodRRIPractices.pdf/0a958291cbbb-4b32-b892-1c5125b8a950]

SHULMAN, L. S. (1986). Those who understand: Knowledge growth in teaching. Educational Researcher, 15, 4-14.

[1] Portal Engaging Science:

http://www.engagingscience.eu/es/

[2] Llicència Creative Commons Attribution - Share Alike:

https://creativecommons.org/licenses/by-sa/3.0/

[3] Curs de Formació per al Professorat Engaging Science:

http://engage.exactls.com/courses/UniversitatDeBa rcelona/ES00/2015_T1/about

[4] Disponible a:

http://engage.exactls.com/courses/UniversitatDeBa rcelona/ES00/2015_T1/

[5] Projecte EuroStem Cell:

http://www.eurostemcell.org/

[6] Projecte PlayDecide:

www.playdecide.eu

[7] Xplore Health:

www.xplorehealth.eu

[8] Jocs de diàleg i cartes de debats:

http://www.xplorehealth.eu/ca/recursos-per-aeducadors?keywords $=\&$ module $=$ All\&categoria $=$ 19

[9] Protocols de treballs pràctics Xplore Health: http://www.xplorehealth.eu/en/resources-foreducators? keywords $=\&$ module $=$ All\&categoria $=2$ 0

[10] Projecte ProGreSs:

http://www.progressproject.eu/

[11] Projecte Socientize:

http://www.socientize.eu/

[12] Projecte Responsible Industry:

http://www.responsible-industry.eu/

[13] Projecte Governance for Responsible Innovation (GREAT):

http://www.great-project.eu/ 